\title{
American Attitudes in Context: Posthumous Use of Cryopreserved Gametes
}

Jason D Hans* and Laura M Frey

Department of Family Sciences, University of Kentucky, USA

\begin{abstract}
Attitudes toward reproducing with a deceased spouse's cryopreserved gametes were examined with a probability sample of 864 respondents from throughout the continental United States. Specifically, a multiple segment factorial vignette was administered to test the effects of five contextual variables: (a) sex composition of the survivor and deceased, (b) marriage duration, (c) deceased's disposition toward parenthood, (d) cause of death, and (e) wishes of the deceased's parents. Roughly two-thirds of respondents were supportive of the procedure across experimental conditions, but support was more likely when the deceased was male, the couple had been married longer, the deceased had been looking forward to parenthood, the death was due to a car accident than suicide, and when the deceased's parents supported the procedure. Rationales for supporting the procedure were primarily focused on the surviving spouse's wishes or rights, the deceased's implied or assumed wishes, and the opinion of the deceased's parents. Those who opposed the procedure most frequently cited the deceased's unknown wishes, concerns for the potential child, and the opinions of the deceased's parents.
\end{abstract}

Keywords: Attitudes; Gamete cryopreservation; Multiple-segment factorial vignette; Posthumous reproduction

\section{Introduction}

Posthumous childbirth has occurred throughout history when a genetic parent (typically the father) of a naturally conceived child dies prior to the child's birth, but reproductive technology now allows posthumous conception using the cryopreserved gametes of deceased individuals. Although posthumous conception is a straightforward medical procedure, it raises complex ethical and legal issues that have resulted in numerous countries-Canada, France, Germany, Norway, and Sweden, among others-banning the procedure $[1,2]$. However, in most countries, including the United States, decisions about posthumous conception are left to individuals and medical professionals.

Fertility clinics in the United States experience a substantial increase in the number of requests by widows wishing to attempt conception using the cryopreserved sperm of a deceased husband starting in the mid-1990s [3,4]. Although no prevalence data has been reported since those collected by Hurwitz et al., indirect evidence suggests that the number of requests for posthumous reproductive services has and will continue to increase. For example, best practice standards of both the American Society of Clinical Oncology [5] and the American Society for Reproductive Medicine [6] now encourage physicians to discuss fertility preservation options with reproductive-aged (and younger) cancer patients as insurance against treatment-induced infertility. Media reports of male soldiers cryopreserving their sperm prior to deployment $[7,8]$, and of military widows attempting to conceive using the sperm of deceased soldiers [9], have likely accelerated overall demand for posthumous reproductive services over the past decade as well. Finally, one may also infer increasing awareness and procurement of posthumous reproductive services based on the rapidly increasing volume of scientific, philosophical, and legal literature addressing the medical, bioethical, social, and legal aspects of posthumous reproduction. The first author maintains a bibliography of all such articles; it contains fewer than 100 articles from all years through 1999 , compared to nearly 200 articles in the subsequent 13 years.

Despite these trends that suggest posthumous reproduction is becoming more prevalent, the bioethical and legal complexities of posthumous reproduction may deter some medical professionals from readily assisting with posthumous reproduction requests [10]. For example, many physicians hold mixed or negative attitudes toward posthumous reproduction; one study found that $16 \%$ of oncologists held favorable attitudes toward posthumous reproduction, compared to $51 \%$ who were ambivalent and $32 \%$ who were opposed to posthumous reproduction [11]. Moreover, best practice standards notwithstanding, many oncologists do not routinely or adequately discuss fertility preservation options with patients [5]. These attitudes and practices contrast with those of cancer patients of reproductive age who are highly concerned about fertility preservation [5], of individuals and couples who cryopreserve their gametes [12], and of the U.S population, which is generally supportive of posthumous reproduction $[13,14]$.

Demographic characteristics such as religion and religiosity are associated with attitudes toward posthumous reproduction in both physicians [11] and the general population [15-17]. That said, contextual circumstances generally have a more profound impact than demographic characteristics on attitudes toward posthumous gamete retrieval [15,16], posthumous use of cryopreserved gametes [17] and the provision of social benefits to posthumously born children [18]. Thus, a better understanding of how contextual factors affect the perceived appropriateness of a request for posthumous reproduction services may help to inform the decision-making processes of medical professionals and policymakers on issues associated with posthumous reproduction. Toward that end, this study examines attitudes in the United States concerning the posthumous use of a spouse's cryopreserved gametes

Corresponding author: Jason D Hans, Department of Family Sciences, 315 Funkhouser Building, University of Kentucky, Lexington, KY 40514, USA, E-mail: jhans@uky.edu

Received February 15, 2013; Accepted March 26, 2013; Published April 03, 2013

Citation: Hans JD, Frey LM (2013) American Attitudes in Context: Posthumous Use of Cryopreserved Gametes. J Clinic Res Bioeth S1: 006. doi:10.4172/21559627.S1-006

Copyright: ( 2013 Hans JD, et al. This is an open-access article distributed under the terms of the Creative Commons Attribution License, which permits unrestricted use, distribution, and reproduction in any medium, provided the original author and source are credited. 
for the purpose of procreation. Specifically, we used multiple-segment factorial vignette design to examine the effects of five contextual variables on attitudes toward the use of cryopreserved gametes for the purpose of posthumous reproduction: (a) sex composition of the survivor and deceased, (b) marriage duration, (c) deceased's disposition toward parenthood, (d) death context, and (e) wishes of the deceased's parents. Prior to describing the design and vignette in greater detail, we briefly explain our rationale for examining each of these variables.

\section{Contextual Issues Addressed in this Study}

\section{Sex composition}

Unlike females, surviving males must procure a gestational surrogate in order to reproduce with the gametes of a deceased woman. Antall argued against allowing men to reproduce posthumously to avoid the potential legal complexities associated with gestational surrogacy [19], and Americans are generally about twice as likely to approve of posthumous reproduction if the deceased is male than female [15-17]. Hans surmised that this "reflects culturally-engrained beliefs about the gendered nature of parenting" (p. 863) because the complexity of surrogacy was curiously absent from the rationales respondents provided for their stated positions. Israel took a more explicit position on gender differences in the context of posthumous reproduction; in 2003 the Israeli Attorney General formalized guidelines which allowed a surviving wife to have the sperm of her deceased husband retrieved posthumously, but no corresponding provision was provided for widowed men [20].

Gendered norms and policies aside, in practice, female gamete cryopreservation is relatively rare compared to male gamete cryopreservation, due both to the complexity of retrieval and the poor success rate of oocyte cryopreservation [5,21]. Consequently, females have more commonly preserved their reproductive potential by cryopreserving embryos, which has been more successful than oocyte cryopreservation. Nevertheless, while there have not yet been any cases reported in the medical or legal literature of cryopreserved oocytes being used in a posthumous context, by 2008 over 900 oocyte cryopreservation babies had been born and that number has been growing exponentially in recent years [22]. Recent advances in oocyte cryopreservation suggest that a reliable method of oocyte cryopreservation will soon be achieved $[23,24]$, thereby democratizing fertility preservation $[21,25]$, and cases where widowed men seek the assistance of reproductive services to conceive using a deceased partner's cryopreserved oocytes with a gestational surrogate will inevitably follow.

\section{Marriage duration}

Hans speculated that relationship duration prior to death could affect perceptions of the appropriateness of posthumous reproduction [15]. Specifically, relative to a long-duration marriage, a short-duration marriage may be viewed as less stable and the surviving spouse may be viewed as less capable of intuiting the deceased's wishes. Conversely, an untimely death may be viewed as the primary reason procreative desires were not fulfilled in a short-duration marriage, compared to a long-duration marriage in which the couple could be viewed as more culpable for delaying and ultimately failing to fulfill any reproductive desires they may have held. Hans, however, found limited support for these postulates when considering the appropriateness of a request for posthumous gamete retrieval; some respondents considered relationship length in their assessments of the situation, but it was not an important factor for most [15]. Analogously, the first known legal case worldwide to address posthumous reproduction [26] involved a widow who had married the deceased only two days prior to his imminent death. She sought, and was awarded, custody of her deceased husband's cryopreserved sperm, which he had cryopreserved prior to cancer treatments to ensure post-treatment fertility options but had not provided instructions what to do with the deposit in the event of death.

\section{Deceased's disposition toward parenthood}

Many who have pursued posthumous reproduction on behalf of deceased partners or relatives have alluded to the deceased's intentions for parenthood prior to the death [26-28]. For example, one mother cited her son's desire to have three sons as the motive for using her child's sperm and a surrogate to have a grandchild [29]. This suggests that the deceased's disposition toward parenthood could play an integral role in motivating survivors to consider posthumous reproduction. Although Hans found that the deceased's plans for parenthood while living did not affect attitudes concerning the appropriateness of posthumously retrieving gametes for the purpose of reproduction [15], no studies have examined the relationship between the deceased's intentions for parenthood and attitudes toward posthumous reproduction in a context where the deceased had cryopreserved gametes prior to death.

Reproductive-aged individuals who cryopreserved gametes typically do so in anticipation of an experience that may leave them infertile, such as a cancer patient preparing for radiation treatments, but sometimes the outcome is death. Contingency instructions in the event of death were rare to nonexistent at cryopreservation clinics in the mid-1990's [4], but clinics are increasingly requiring depositors to indicate what should be done with their gametes or embryos in the event of death $[3,30]$. In addition, some individuals prepare wills or other written documents with explicit instructions concerning their cryopreserved gametes in advance of an imminent death, such as by cancer or suicide [27,31]. However, instructions from the deceased for the disposition of cryopreserved gametes in the event of death are often not available, which leaves clinics and courts to navigate ethical and legal quandaries concerning the appropriate course of action.

Attempting to intuit the deceased's wishes in such cases is difficult if not impossible. A desire to have a child is often assumed to be a basic human instinct $[32,33]$ and some have suggested that marriage itself implies intent to procreate [34]. However, these positions are debatable and weaken as the fertility rate declines [35] and more couples choose voluntary childlessness [36]. The act of cryopreservation may strengthen the assumption of intent to reproduce; at a minimum, cryopreservation can be taken to imply intent to preserve reproductive potential for possible future use in one's lifetime. Nevertheless, evidence of a desire to reproduce in the course of one's life is not clear evidence of one's willingness to reproduce after death. For example, Robertson argued that posthumous reproduction provides the deceased none of the satisfaction or experiences that are most commonly and profoundly associated with parenthood because the deceased will never know whether offspring have been conceived, nor will the deceased act as a parent for any resulting offspring [37]. For similar reasons, Cannold, Parker, and Oakley argued against posthumous reproduction in a case where a couple had not yet conceived at the time of the man's unexpected death but had already picked names, decorated a bedroom as a nursery, and established "family" insurance [38-40]; Moreover, the deceased had previously donated sperm to be used for fertility purposes while a university student some years earlier, and the parents of both the surviving and deceased partners were supportive of the retrieval request [41]. 


\section{Cause of death}

In the absence of explicit instructions from the deceased, cause of death-more specifically, whether the death could be anticipated and the deceased's state of mind at the time of death-could be a factor that affects the perceived appropriateness of posthumous reproduction. For example, posthumous reproduction may be viewed as more acceptable if the deceased could not have reasonably anticipated and prepared for death, as in the case of a car accident, than if the death was foreseeable yet the deceased remained silent on the issue of posthumous reproduction. In addition, posthumous reproduction could be viewed as more acceptable for those who did not intentionally bring death upon themselves than for those who are culpable in their own death, as in the case of suicide [27], Russian roulette [42], or fist fighting [43].

\section{Wishes of the deceased's parents}

Intentions of surviving partners to pursue posthumous reproduction are sometimes opposed by the deceased's parents. However, courts have dismissed parental objections in cases where the deceased was married [44] or where the deceased's intentions were clear [31]. Similarly, Israel's progressive posthumous reproduction guidelines, which presume the deceased's consent unless stated otherwise, explicitly deny parents legal standing to pursue posthumous reproduction for deceased children because "parents should not be involved in the decision to have children, neither when the husband is alive nor after his death"[45-47].

Legal standing aside, parents have an understandable interest in whether their children produce offspring and in the disposition of their deceased children's remains. Guidelines established at Cornell University and used in many New York hospitals stipulate that only a wife can consent to postmortem sperm retrieval but that "any detectable conflict among interested parties should be a contraindication to postmortem sperm retrieval" [48].Thus, according to this policy, a medical professional or fertility clinic could justly be dissuaded from fulfilling a posthumous reproduction request if the deceased's parents are unsupportive. This approach seems consistent with the views of many Americans too, who are about half as likely to be supportive of a surviving partner's desire for posthumous gamete retrieval when the deceased's parents are opposed, compared to when the parents are supportive of the surviving partner's intentions $[15,16]$.

\section{Method}

\section{Participants}

Respondents were contacted using a list-assisted random-digit dialing method giving every household telephone in the continental United States an equal probability of being contacted [49]. To reduce within-unit sampling bias, the respondent within each household was randomly selected according to the youngest or oldest adult of a given sex living in the household. Multiple call attempts were made to each telephone number in the sample, and a conversion attempt was made for each initial refusal. These procedures resulted in a response rate of $20 \%$, which compares favorably to current telephone survey response rates and, although low relative to past decades, does not compromise the representativeness of the sample [50].

The sample of 864 respondents consisted of 347 (40\%) males and $517(60 \%)$ females from across the continental United States and ranging in years of age from 18 to $97(\mathrm{M}=51 ; \mathrm{SD}=16)$. The majorities of respondents were White (84\%), had ever been married (84\%), had never been widowed (88\%), and had children (74\%). Level of formal education was more diverse: $24 \%$ had at least some post-Bachelor's degree education, $23 \%$ had attained a Bachelor's degree, $28 \%$ had some higher education but had not attained a Bachelor's degree, and 25\% had a high school diploma or less. Compared to the U.S. population, the sample overrepresented females, Whites, college educated, and ever married [51,52].

The distribution of religious affiliation was generally consistent with the U.S. population as reported by the Pew Forum on Religion and Public Life [53];about half (51\%) of respondents classified themselves as Protestant, followed by Catholic (27\%) and Jewish (3\%); another 11\% classified their religious identity as something else and 6\% indicated that they had no religious preference. One-third of respondents (33\%) reported that they were very religious; a similar percentage $(34 \%)$ indicated that they were somewhat religious, $13 \%$ classified themselves as slightly religious, and $15 \%$ said they were not religious.

\section{Design and procedures}

Multiple-segment factorial vignettes (MSFVs) combine the random manipulation of variables in factorial designs and the contextual richness of multiple-segment vignettes [54]. The MSFV method is ideally suited for examining beliefs and attitudes about rare social phenomena, as well as the effects that contextual circumstances have on those beliefs and attitudes. The MSFV designed for this study described a fictional situation in which a widowed individual wished to use the cryopreserved gametes of his or her deceased spouse to conceive a child. The vignette consisted of three segments, or paragraphs, each followed by a series of questions. Respondents were randomly presented one of 32 versions of the vignette, which varied by manipulation of five independent design variables that were imbedded within the vignette: (a) marriage length, (b) sex of the deceased, (c) deceased's disposition toward parenthood, (d) cause of death, and (e) disposition of decease's parents.

The first segment indicated that the marriage had lasted either a few months or a few years when either the husband or wife died, and that the deceased spouse had either been looking forward to or hesitant about becoming a parent. In the following example, the marriage had lasted a few years when the male, who had been looking forward to parenthood, suddenly died:

Rick and Vanessa had been married for a few years when Rick died suddenly. Not long before his death the couple had been talking about having a child together, and he was looking forward to becoming a parent. After some time has passed following the death, Vanessa finds a document in Rick's things showing that he had frozen some sperm at a fertility clinic a few years before they had met. Although uncertain about why he had frozen his sperm, Vanessa decides that she would like to have a biological child with Rick using the frozen sperm if they are still available at the fertility clinic (Segment 1 example). After this segment of the vignette was read to respondents, they were then asked: (a) "Do you think Vanessa should or should not be able to have a child using her deceased husband's frozen sperm?"and "How obligated are medical professionals to follow Vanessa's wishes; would you say highly obligated, moderately obligated, slightly obligated, or not at all obligated?" Respondents were then instructed, "Briefly explain in your own words why you chose these answers," and their responses were typed verbatim.

The second vignette segment continued the story from the first segment by revealing that the death had resulted from either a car accident or suicide: 
Vanessa went to the fertility clinic with the document she had found and explained that her husband had died in a car accident nearly a year earlier and that she would like to use the sperm he had frozen several years earlier. The clinic was undecided about whether or not to release the sperm to Vanessa because the sperm had been deposited before Rick and Vanessa had even known each other (Segment 2 example). After hearing the second vignette segment, respondents were once again asked the following questions: (a) "Given this new information, do you think Vanessa should or should not be able have a child using her deceased husband's frozen sperm?" and (b) "How obligated are medical professionals to follow Vanessa's wishes; would you say highly obligated, moderately obligated, somewhat obligated, or not at all obligated?" Once again, respondents were also asked to provide a rationale for their answers.

The final vignette segment indicated whether the deceased's parents were supportive or not supportive of the surviving spouse's desire to conceive using the cryopreserved gametes of their son or daughter:

Upon contacting Rick's parents, who had been listed as next-ofkin at the time the sperm were frozen, the clinic learned that the parents were supportive of Vanessa's desire to use their son's frozen sperm (Segment 3 example). The same two questions that were asked following the second segment were then repeated, followed by the request to provide a rationale for those responses.

\section{Analytic approach}

Logistic regression models were created for each of the three questions that asked whether conception using the deceased's cryopreserved gametes should or should not be allowed, and ordinal regression models were created for each of the three questions about medical professionals' obligation to assist. In all six regression models, the main effects of the independent design variables and respondent characteristics were forced into the models.

The rationales respondents provided for their responses to the closed-ended questions were typed verbatim and coded inductively using conventional content analysis techniques [55]. The coding unit was a unique rationale, so a single response may have been coded into multiple categories. Approximately one-third of the responses were coded by a second coder to test for inter-rater reliability, which resulted in a substantial amount of agreement $(\mathrm{kappa}=0.61)$ between the two coders [56].

\section{Results}

\section{Should posthumous reproduction using cryopreserved gametes be allowed?}

Opinions about whether fertility services should be allowed using the cryopreserved gametes of a deceased spouse were generally favorableabout two-thirds indicated that these services should be allowed-but responses varied according to the contextual circumstances presented in the vignette. For example, following the first vignette segment, about $50 \%$ of respondents who heard about a deceased female that had been married for a few months and was undecided about having children were supportive of the surviving spouse's request, compared to over $79 \%$ who heard about a deceased male that had been married for a few years and wanted to have children prior to his death. Similarly, those who heard the death resulted from a car accident or that the deceased's parents were supportive of the survivor's request were more likely to indicate that the procedure should be allowed than were those who heard that the cause of death was suicide or that the deceased's parents were opposed to the request, respectively (see Table 1 for descriptive statistics).

The logistic regression models (see Table 2) indicate that all five of the independent design variables influenced respondents' attitudes concerning whether the surviving spouse should or should not be allowed to use the deceased spouse's cryopreserved gametes. Specifically, respondents were more likely to indicate that the surviving spouse should be able to have a child using his or her deceased spouse's cryopreserved gametes if they heard that (a) the surviving spouse was a female rather than a male, (b) the couple was portrayed as having been married years rather than months, (c) the deceased spouse was looking forward to having a child rather than had mixed feelings about having a child, (d) the cause of death was a car accident rather than suicide, and (e) the deceased's parents were supportive rather than not supportive of the surviving spouse's intentions. In addition, the effects of the variables were remarkably similar; all point estimates of the odds ratios roughly ranged from 1.3 to 1.6 with the exception of parental disposition $(\mathrm{OR}=2.86)$. Aside from religion-Catholics and Protestants tended to hold less favorable attitudes than those with no religious preference, although the precision of those estimates were too wide in these data to draw population-level conclusions-responses did not vary in predictable or meaningful ways according to respondent characteristics.

\section{How obligated are medical professionals to assist?}

Across vignette conditions, about half to two-thirds of respondents indicated that medical professionals were moderately or highly obligated to follow the wishes of the surviving spouse, compared to roughly a quarter of respondents who indicated that medical professionals had no obligation at all to assist (see Table 3 for descriptive statistics). Although less pronounced, the effects of the independent design variables on perceived obligation to assist were largely consistent with attitudes concerning whether the procedure should be allowed. Specifically, respondents attributed a higher degree of obligation on the part of medical professionals to assist if they heard that the deceased's parents were supportive rather than opposed, that the cause of death was a car accident rather than a suicide, or that the deceased wanted

\begin{tabular}{lcccc}
\hline & \multicolumn{4}{c}{ Should or should not be allowed? } \\
\cline { 2 - 5 } Independent variable & $n$ & Should not & Should & Don't know \\
\hline Marriage length & & & & \\
$\quad$ Few months & 415 & 29.2 & 63.9 & 7.0 \\
$\quad$ Few years & 446 & 26.2 & 68.6 & 5.2 \\
Sex of deceased & & & & \\
$\quad$ Male & 434 & 25.3 & 70.7 & 3.9 \\
$\quad$ Female & 427 & 30.0 & 61.8 & 8.2 \\
Parenthood plans & & & & \\
$\quad$ Undecided about children & 420 & 31.4 & 61.4 & 7.1 \\
$\quad$ Wanted to have children & 441 & 24.0 & 71.0 & 5.0 \\
Cause of death & & & & \\
$\quad$ Car accident & 424 & 35.4 & 57.8 & 6.8 \\
$\quad$ Suicide & 436 & 45.4 & 46.3 & 8.3 \\
Deceased's parents' wishes & & & & \\
$\quad$ Opposed & 435 & 46.4 & 45.7 & 7.8 \\
$\quad$ Supportive & 425 & 26.6 & 68.7 & 4.7 \\
\hline
\end{tabular}

Table 1: Percentage of responses within each level of the independent variables. 
Citation: Hans JD, Frey LM (2013) American Attitudes in Context: Posthumous Use of Cryopreserved Gametes. J Clinic Res Bioeth S1: 006. doi:10.4172/2155-9627.S1-006

Page 5 of 8

\begin{tabular}{|c|c|c|c|c|c|c|c|c|c|c|c|c|c|c|c|}
\hline \multirow[b]{2}{*}{ Predictor } & \multicolumn{5}{|c|}{$\begin{array}{c}\text { Segment } 1 \\
n=755, \text { should }=71 \%\end{array}$} & \multicolumn{5}{|c|}{$\begin{array}{c}\text { Segment } 2 \\
n=742, \text { should }=57 \%\end{array}$} & \multicolumn{5}{|c|}{$\begin{array}{c}\text { Segment } 3 \\
n=752, \text { should }=62 \%\end{array}$} \\
\hline & $\mathrm{B}$ & SE & $\mathrm{p}$ & OR & $95 \% \mathrm{Cl}$ & $\mathrm{B}$ & SE & $\mathrm{p}$ & OR & $95 \% \mathrm{Cl}$ & B & SE & $\mathrm{p}$ & OR & $95 \% \mathrm{Cl}$ \\
\hline Marriage a few months (years) & -0.31 & 0.17 & .066 & 0.74 & {$[0.53,1.02]$} & -0.27 & 0.15 & .077 & 0.76 & {$[0.56,1.03]$} & -0.48 & 0.16 & .003 & 0.62 & {$[0.45,0.85]$} \\
\hline Deceased male (female) & 0.37 & 0.17 & .027 & 1.45 & {$[1.04,2.00]$} & 0.43 & 0.16 & .006 & 1.53 & {$[1.13,2.07]$} & 0.49 & 0.16 & .002 & 1.63 & {$[1.19,2.24]$} \\
\hline Undecided about children (wanted children) & -0.44 & 0.17 & .009 & 0.65 & {$[0.47,0.90]$} & -0.27 & 0.16 & .085 & 0.77 & {$[0.57,1.04]$} & -0.42 & 0.16 & .009 & 0.66 & {$[0.48,0.90]$} \\
\hline Died by car accident (suicide) & & & & & & 0.42 & 0.16 & .007 & 1.52 & {$[1.12,2.06]$} & 0.46 & 0.16 & .005 & 1.58 & {$[1.15,2.17]$} \\
\hline Deceased's parents opposed (supportive) & & & & & & & & & & & -1.04 & 0.16 & $<.001$ & 0.35 & {$[0.26,0.49]$} \\
\hline \multicolumn{16}{|l|}{ Respondent characteristics } \\
\hline Age & 0.00 & 0.01 & 670 & 1.00 & {$[0.99,1.02]$} & -0.01 & 0.01 & .380 & 1.00 & {$[0.98,1.01]$} & -0.01 & 0.01 & .332 & 0.99 & {$[0.98,1.01]$} \\
\hline Education & -0.19 & 0.07 & .007 & 0.83 & {$[0.72,0.95]$} & -0.03 & 0.07 & .697 & 0.98 & {$[0.86,1.11]$} & -0.09 & 0.07 & .184 & 0.91 & {$[0.80,1.05]$} \\
\hline Income & -0.01 & 0.07 & .923 & 0.99 & {$[0.87,1.13]$} & 0.01 & 0.06 & .984 & 1.00 & {$[0.89,1.13]$} & -0.01 & 0.07 & .851 & 0.99 & {$[0.87,1.12]$} \\
\hline Male (female) & 0.15 & 0.17 & .400 & 1.16 & {$[0.82,1.62]$} & 0.13 & 0.16 & .406 & 1.14 & {$[0.84,1.56]$} & 0.10 & 0.17 & .542 & 1.11 & {$[0.80,1.53]$} \\
\hline Never been married (has been married) & 0.47 & 0.31 & .121 & 1.60 & {$[0.88,2.92]$} & 0.23 & 0.27 & .401 & 1.26 & {$[0.74,2.15]$} & 0.13 & 0.28 & 651 & 1.14 & {$[0.65,1.98]$} \\
\hline Never been widowed (has been widowed) & 0.25 & 0.27 & .359 & 1.28 & {$[0.75,2.19]$} & 0.10 & 0.26 & .713 & 1.10 & {$[0.66,1.82]$} & 0.02 & 0.26 & .940 & 1.02 & {$[0.61,1.71]$} \\
\hline Never had children (has had children) & -0.25 & 0.23 & .284 & 0.78 & {$[0.49,1.23]$} & -0.46 & 0.23 & .042 & 0.63 & {$[0.40,0.98]$} & -0.17 & 0.24 & .464 & 0.84 & {$[0.53,1.33]$} \\
\hline Religiosity & -0.12 & 0.09 & .171 & 0.89 & {$[0.74,1.05]$} & -0.04 & 0.08 & .620 & 0.96 & {$[0.82,1.13]$} & -0.03 & 0.09 & .737 & 0.97 & {$[0.82,1.15]$} \\
\hline \multicolumn{16}{|l|}{ Religion } \\
\hline Catholic (no preference) & -0.26 & 0.42 & .536 & 0.77 & {$[0.34,1.75]$} & -0.54 & 0.40 & .173 & 0.58 & {$[0.27,1.27]$} & -0.79 & 0.45 & .079 & 0.46 & {$[0.19,1.10]$} \\
\hline Jewish (no preference) & 1.04 & 0.73 & .155 & 2.83 & {$[0.68,11.85]$} & 1.19 & 0.72 & .100 & 3.28 & {$[0.80,13.56]$} & -0.08 & 0.66 & .907 & 0.93 & {$[0.26,3.35]$} \\
\hline Protestant ${ }^{\text {(no preference) }}$ & -0.07 & 0.41 & .875 & 0.94 & {$[0.42,2.10]$} & -0.55 & 0.39 & .162 & 0.58 & {$[0.27,1.25]$} & -0.67 & 0.44 & .134 & 0.51 & {$[0.22,1.23]$} \\
\hline
\end{tabular}

Note: Reference category in parentheses. $\mathrm{Cl}=$ confidence interval for odds ratio (OR)

Table 2: Logistic regression predicting whether use of deceased spouse's cryopreserved gametes should be allowed

\begin{tabular}{|c|c|c|c|c|c|c|}
\hline \multirow[b]{2}{*}{ Independent variable } & \multicolumn{6}{|c|}{ How obligated are medical professionals to assist? } \\
\hline & $n$ & Not at all & Slightly & Moderately & Highly & Don't know \\
\hline \multicolumn{7}{|l|}{ Marriage length } \\
\hline Few months & 417 & 24.2 & 8.6 & 24.5 & 36.2 & 6.5 \\
\hline Few years & 446 & 22.6 & 10.1 & 22.0 & 39.5 & 5.8 \\
\hline \multicolumn{7}{|l|}{ Sex of deceased } \\
\hline Male & 435 & 22.8 & 8.0 & 23.2 & 40.9 & 5.1 \\
\hline Female & 428 & 24.1 & 10.7 & 23.1 & 34.8 & 7.2 \\
\hline \multicolumn{7}{|l|}{ Parenthood plans } \\
\hline Undecided about children & 422 & 27.5 & 9.2 & 21.6 & 35.3 & 6.4 \\
\hline Wanted to have children & 441 & 19.5 & 9.5 & 24.7 & 40.4 & 5.9 \\
\hline \multicolumn{7}{|l|}{ Cause of death } \\
\hline Car accident & 424 & 31.6 & 8.0 & 22.2 & 33.0 & 5.2 \\
\hline Suicide & 436 & 35.6 & 13.1 & 20.4 & 26.1 & 4.8 \\
\hline \multicolumn{7}{|l|}{ Deceased's parents' wishes } \\
\hline Opposed & 435 & 40.0 & 8.5 & 20.5 & 26.7 & 4.4 \\
\hline Supportive & 426 & 26.5 & 10.3 & 20.2 & 39.0 & 4.0 \\
\hline
\end{tabular}

Table 3: Percentage of responses within each level of the independent variables.

children rather than was undecided about children. The effects of the deceased's sex and length of the marriage were slightly weaker, but remained consistent with attitudes toward the procedure itself. Complete results from the ordinal regression analyses are presented in Table 4.

\section{Rationales for responses}

Responses to the open-ended items provided insight into the reasons why participants answered differently according to the vignette version they heard. The most frequent rationales are summarized in Table 5. Among those who supported the use of cryopreserved gametes, the most common rationale emphasized the surviving spouse's wishes or rights with respondents, such as "A husband has say over his wife's body (following her death)," "It's his choice, not the doctor's [choice]," and "It's her right as a wife." Others who supported the use of cryopreserved gametes focused on the deceased's wishes; examples include "He would want to have children" and "She had her eggs frozen for a purpose."

Among respondents who did not support the procedure, the primary rationale cited was the unknown wishes of the deceased. Examples of this rationale include, "She should have discussed it previously" and "He never said it was okay". Next most common among the rationales provided for not supporting the procedure was concern for the potential child's well-being, such as "Two parents are needed to raise a child" and "The child's emotional health would be a concern."

Also noteworthy among the response patterns was that, following 
Citation: Hans JD, Frey LM (2013) American Attitudes in Context: Posthumous Use of Cryopreserved Gametes. J Clinic Res Bioeth S1: 006. doi:10.4172/2155-9627.S1-006

Page 6 of 8

\begin{tabular}{|c|c|c|c|c|c|c|c|c|c|c|c|c|c|c|c|}
\hline \multirow[b]{2}{*}{ Predictor } & \multicolumn{5}{|c|}{$\begin{array}{c}\text { Segment } 1 \\
n=755\end{array}$} & \multicolumn{5}{|c|}{$\begin{array}{c}\text { Segment } 2 \\
n=742\end{array}$} & \multicolumn{5}{|c|}{$\begin{array}{c}\text { Segment } 3 \\
n=752\end{array}$} \\
\hline & B & SE & $\mathrm{p}$ & OR & $95 \% \mathrm{Cl}$ & B & SE & $\mathrm{p}$ & OR & $95 \% \mathrm{Cl}$ & B & SE & $\mathrm{p}$ & OR & $95 \% \mathrm{Cl}$ \\
\hline Marriage a few months (years) & -0.17 & 0.14 & .203 & 0.84 & {$[0.65,1.10]$} & -0.17 & 0.13 & .193 & 0.84 & {$[0.65,1.09]$} & -0.20 & 0.14 & .133 & 0.82 & {$[0.63,1.06]$} \\
\hline Deceased male (female) & 0.23 & 0.14 & .096 & 1.25 & {$[0.96,1.63]$} & 0.33 & 0.13 & .016 & 1.38 & {$[1.06,1.80]$} & 0.35 & 0.14 & .010 & 1.41 & {$[1.09,1.84]$} \\
\hline Undecided about children (wanted children) & -0.30 & 0.14 & .026 & 0.74 & {$[0.57,0.96]$} & -0.18 & 0.13 & .172 & 0.83 & {$[0.64,1.08]$} & -0.24 & 0.14 & .080 & 0.79 & {$[0.61,1.03]$} \\
\hline Died by car accident (suicide) & & & & & & 0.31 & 0.14 & .024 & 1.36 & {$[1.04,1.77]$} & 0.26 & 0.14 & .054 & 1.30 & {$[1.00,1.69]$} \\
\hline Deceased's parents opposed (supportive) & & & & & & & & & & & -0.62 & 0.14 & $<.001$ & 0.54 & {$[0.41,0.70]$} \\
\hline \multicolumn{16}{|l|}{ Respondent characteristics } \\
\hline Age & -0.01 & 0.01 & .255 & 0.99 & {$[0.98,1.00]$} & -0.01 & 0.01 & .047 & 0.99 & {$[0.98,1.00]$} & -0.01 & 0.01 & .076 & 0.99 & {$[0.98,1.00]$} \\
\hline Education & 0.02 & 0.06 & .789 & 1.02 & {$[0.91,1.14]$} & -0.06 & 0.06 & .275 & 0.94 & {$[0.84,1.05]$} & -0.10 & 0.06 & .081 & 0.91 & {$[0.81,1.01]$} \\
\hline Income & -0.03 & 0.06 & .618 & 0.97 & {$[0.87,1.08]$} & -0.07 & 0.05 & .182 & 0.93 & {$[0.84,1.03]$} & -0.09 & 0.05 & .108 & 0.92 & {$[0.82,1.02]$} \\
\hline Male (female) & 0.08 & 0.14 & .545 & 1.09 & {$[0.83,1.43]$} & 0.07 & 0.14 & .598 & 1.08 & {$[0.82,1.41]$} & 0.01 & 0.14 & .923 & 1.01 & {$[0.77,1.33]$} \\
\hline Never been married (has been married) & 0.16 & 0.24 & .491 & 1.18 & {$[0.74,1.87]$} & 0.45 & 0.24 & .056 & 1.57 & {$[0.99,2.49]$} & 0.50 & 0.24 & .035 & 1.64 & {$[1.03,2.61]$} \\
\hline Never been widowed (has been widowed) & -0.23 & 0.23 & .321 & 0.80 & {$[0.51,1.25]$} & -0.23 & 0.23 & .302 & 0.79 & {$[0.51,1.23]$} & -0.29 & 0.23 & .196 & 0.75 & {$[0.48,1.16]$} \\
\hline Never had children (has had children) & -0.13 & 0.19 & .512 & 0.88 & {$[0.60,1.29]$} & -0.41 & 0.20 & .035 & 0.66 & {$[0.45,0.97]$} & -0.34 & 0.19 & .080 & 0.71 & {$[0.49,1.04]$} \\
\hline Religiosity & -0.06 & 0.07 & .415 & 0.94 & {$[0.82,1.09]$} & -0.04 & 0.07 & .621 & 0.97 & {$[0.84,1.11]$} & -0.03 & 0.07 & .724 & 0.98 & {$[0.85,1.12]$} \\
\hline \multicolumn{16}{|l|}{ Religion } \\
\hline Catholic ${ }^{\text {(no preference) }}$ & -0.07 & 0.33 & .835 & 0.93 & {$[0.49,1.77]$} & -0.27 & 0.33 & .409 & 0.76 & {$[0.40,1.45]$} & -0.28 & 0.33 & .397 & 0.76 & {$[0.40,1.44]$} \\
\hline Jewish ${ }^{\text {(no preference) }}$ & 0.73 & 0.51 & .153 & 2.08 & {$[0.76,5.67]$} & 0.63 & 0.50 & .208 & 1.87 & {$[0.71,4.94]$} & 0.36 & 0.48 & .461 & 1.43 & {$[0.55,3.68]$} \\
\hline Protestant ${ }^{\text {(no preferennce) }}$ & -0.22 & 0.32 & .498 & 0.80 & {$[0.43,1.51]$} & -0.41 & 0.32 & .206 & 0.66 & {$[0.35,1.25]$} & -0.35 & 0.32 & .273 & 0.70 & {$[0.38,1.32]$} \\
\hline
\end{tabular}

Note: Reference category in parentheses. $\mathrm{Cl}=$ confidence interval for odds ratio (OR)

Table 4: Ordinal regression predicting how obligated medical professional are to assist survivor with use of deceased spouse's cryopreserved gametes

\begin{tabular}{|c|c|c|c|c|c|c|}
\hline \multirow[b]{2}{*}{ Rationale } & \multicolumn{2}{|c|}{ Segment 1} & \multicolumn{2}{|c|}{ Segment 2} & \multicolumn{2}{|c|}{ Segment 3} \\
\hline & $n$ & $\%$ & $n$ & $\%$ & $n$ & $\%$ \\
\hline Should & 564 & & 437 & & 481 & \\
\hline Survivor's wishes or rights & 201 & 35.6 & 181 & 41.4 & 132 & 27.4 \\
\hline Deceased's wishes & 102 & 18.1 & 51 & 11.7 & 26 & 5.4 \\
\hline Parents' opinion important & & & & & 98 & 20.4 \\
\hline Parents' opinion irrelevant & & & & & 75 & 15.6 \\
\hline Should not & 230 & & 338 & & 300 & \\
\hline Deceased's wishes unknown & 54 & 23.5 & 88 & 26.0 & 48 & 16.0 \\
\hline Concerns for child & 37 & 16.1 & 43 & 12.7 & 31 & 10.3 \\
\hline Frozen for different purpose/person & 22 & 9.6 & 47 & 13.9 & 21 & 7.0 \\
\hline Unnatural or religion & 17 & 7.4 & 17 & 5.0 & 14 & 4.7 \\
\hline Move on with life & 14 & 6.1 & 12 & 3.6 & 10 & 3.3 \\
\hline Suicide & & & 22 & 6.5 & 8 & 2.7 \\
\hline Parents' opinion important & & & & & 57 & 19.0 \\
\hline
\end{tabular}

Table 5: Most common rationales for whether posthumous conception should or should not be allowed.

the third segment, about one-third of those who supported the procedure and a quarter of those who were opposed addressed the parents' position while providing their rationale. Examples include "The parents' opinions should be considered out of respect" and "The parents don't agree with it being done." However, this rationale was notably uncommon among one subgroup. Specifically, those who heard about supportive parents but who disapproved of the procedure themselves tended to ignore the parents' disposition in favor of more generalized rationales to explain their position. Overall, however, the frequency with which respondents referenced the parents' disposition in their rationales, in conjunction with the relatively large odds ratio of this variable in the regression models, provides corroborating evidence of the important impact of this variable relative to others as respondent's formed their position on the issue in the given context.

\section{Discussion}

The purpose of this study was to examine the effects of contextual circumstances on attitudes toward widowed individuals using cryopreserved gametes to produce a child in common with a deceased spouse. Findings indicate that the perceived appropriateness of posthumous conception using a spouse's cryopreserved gametes is dependent on contextual circumstances, including sex composition of the survivor and deceased, marriage duration, the deceased's disposition toward parenthood, cause of death, and wishes of the deceased's parents.

Our findings concerning the influence of sex composition on attitudes augment previous research [15,17], which has found a consistent but unwitting gender bias that favors women over men for reproducing following a partner's death. The dearth of open-ended responses referencing the sex composition of the deceased and living, or biological reproductive differences, provides compelling evidence that the source of the bias is deeply rooted, we suspect, in the functional parenting roles applied to males and females [57]. These gendered cultural norms suggest that women are naturally more expressive and nurturing than men and are therefore better suited as caregivers for young children. This notion is further supported by the fact that 
over $73 \%$ of single-parent households in the United States are headed by mothers [58], as well as by evidence indicating that hours of paid employment predict neither hour spent on child care nor the difference in hours spent on child care between men and women [59].

Our findings also contribute to literature indicating that relationship context affects attitudes toward the suitability of posthumous reproduction. While previous studies [15-17] have examined the effects of marital status comparing cohabiting versus married partners, only Hans had examined marital length, and did so in the context of posthumous gamete retrieval [15]. Our results in the context of cryopreserved gametes were consistent with those of Hans in finding that marital length has only small but consistent effects favoring those who had been married longer.

Two previous studies in the extant literature examined the role that circumstances of death may play in shaping attitudes toward posthumous reproduction and identified effects that were too small to be statistically detected. Specifically, Hans and Yelland found that respondents who heard about the combat-related death of a soldier were $4 \%$ more likely to approve of posthumous gamete retrieval than were those who heard about a bungee-jumping death [16], and Hans found that respondents who heard about a death by cancer were about $20 \%$ more likely to approve of posthumous gamete retrieval than were those who heard about a death by car accident [15]. Our results, however, indicated that the odds of approval were more than $50 \%$ greater for those who died by car accident compared to suicide. Although only $5.5 \%$ of respondents who heard about a suicide mentioned suicide when explaining their position on the procedure, among those respondents the view that suicide is a contraindication for reproductive fitness was rooted in concerns about the mental health of subsequent offspring. This attitude is reminiscent of research indicating that an individual's risk for suicide increases with the presence of suicide by a family member $[60,61]$, although it remains unclear whether the transmission of suicide risk is attributable to a hereditary trait, social learning, life context, or some combination of the three. Alternatively, a more direct explanation for why some respondents viewed suicide as a contraindication for posthumous reproduction may be the stigma and negative attitudes associated with mental health issues in general $[62,63]$. For example, suicidal patients have reported stigmatizing attitudes related to mental disorders, such as being viewed as weak or responsible for the disorder [64].

Our finding that the deceased's disposition toward parenthood affected beliefs about whether the procedure should be performed compliments extant literature regarding the importance of the deceased's wishes for assessing posthumous reproduction requests $[16,17]$. These findings underscore the need for cryopreservation clinics to obtain written documentation with explicit instructions from the depositor concerning the desired and acceptable uses of cryopreserved gametes in the event of death. Legal wills can also provide crucial legal guidance in the context of posthumous reproduction, yet few people of reproductive age have wills and far fewer stipulate the desired and acceptable uses of their reproductive material with reference to the possibility of posthumous reproduction (the caveat being that reproductive material is included in the Anatomical Gift Act [15]).

Parents often hold legal sway in any decision-making process associated with posthumous reproduction following the death of unmarried children, but they do not typically have any legal status when their children are married. Nonetheless, parental disposition had the most pronounced effect on attitudes of any variable examined in this study despite that fact that all vignette characters were portrayed as married. It seems likely that this deference to parental disposition is rooted in concerns for the family climate into which resulting offspring may be born given that this effect has been relatively consistent across studies regardless of the deceased's marital status, the deceased's wishes, or the type of posthumous reproduction [15-17].

\section{Conclusion}

The technology and medical advances associated with posthumous reproduction has progressed rapidly in recent decades. Demand for posthumous reproductive services will always remain sparse due to the uncommon circumstances that prompt these requests, yet access to the procedure carries a substantial amount of meaning for those who find themselves in these rare and undesirable circumstances. Although these procedures present many complex ethical and legal dilemmas, this study indicates that the U.S. population is generally supportive of posthumous reproduction using the cryopreserved gametes of a deceased partner but that the level of support varies according to contextual circumstances. Although these contextual distinctions are often subtle, they can help to guide medical professionals and policymakers toward practice and policy that is deemed suitable and respectful to all parties involved in these cases.

\section{References}

1. Bahadur G (1996) Posthumous assisted reproduction. Posthumous assisted reproduction (PAR): cancer patients, potential cases, counselling and consent. Hum Reprod 11: 2573-2575.

2. Lansac J (1996) French law concerning medically-assisted reproduction. Hum Reprod 11: 1843-1847.

3. Hurwitz JM, Macdonald JA, Lifschitz LV, Batzer FR, Caplan A (2002) Posthumous sperm procurement: An update. Fertility and Sterility 78: S242.

4. Kerr SM, Caplan A, Polin G, Smugar S, O'Neill K, et al. (1997) Postmortem sperm procurement. J Urol 157: 2154-2158.

5. Lee SJ, Schover LR, Partridge AH, Patrizio P, Wallace $W H$, et al. (2006) American Society of Clinical Oncology recommendations on fertility preservation in cancer patients. J Clin Oncol 24: 2917-2931.

6. Ethics Committee of the American Society for Reproductive Medicine (2005) Fertility preservation and reproduction in cancer patients. Fertil Steril 83: 1622 1628.

7. McDougall $L$ (2003) Soldiers preserve sperm as fear of new Gulf war grows

8. Tobin D (2008) War-bound soldiers are banking their sperm in CNY. The Post Standard.

9. Montet V, Delfour-Given S (2007) Two years after US soldier's death, widow has his son. Yahoo News.

10. Laborde E, Sandlow J, Brannigan RE (2011) Postmortem sperm retrieval. J Androl 32: 467-469.

11. Quinn GP, Knapp CA, Malo TL, McIntyre J, Jacobsen PB, et al. (2012) Physicians' undecided attitudes toward posthumous reproduction: fertility preservation in cancer patients with a poor prognosis. J Support Oncol 10 160-165.

12. Nakhuda GS, Wang JG, Sauer MV (2011) Posthumous assisted reproduction: a survey of attitudes of couples seeking fertility treatment and the degree of agreement between intimate partners. Fertil Steril 96: 1463-1466.

13. Hans JD (2013) Posthumous gamete retrieval and reproduction: Would the deceased spouse consent? Manuscript submitted for publication.

14. Mizukami A, Peterson CM, Huang I, Cook C, Boyack LM, et al. (2005) The acceptability of posthumous human ovarian tissue donation in Utah. Hum Reprod 20: 3560-3565.

15. Hans JD (2008) Attitudes toward posthumous harvesting and reproduction Death Stud 32: 837-869.

16. Hans JD, Yelland, E (2013) Posthumous sperm retrieval for cryopreservation and reproduction: Attitudes in context. J Clinic Res Bioeth S1: 008. 
Citation: Hans JD, Frey LM (2013) American Attitudes in Context: Posthumous Use of Cryopreserved Gametes. J Clinic Res Bioeth S1: 006. doi:10.4172/2155-9627.S1-006

Page 8 of 8

17. Hans JD, Dooley B (2013) Attitudes toward making babies: with a deceased partner's cryopreserved gametes. Death Stud: in press.

18. Hans JD, Gillen M (2013) Social Security survivor's benefit: The effects of reproductive pathway and intestacy law on attitudes. Journal of Law, Medicine and Ethics 41: 514-524

19. Antall KL (1999) Who is my mother?: why states should ban posthumous reproduction by women. Health Matrix Clevel 9: 203-234.

20. Siegel-Itzkovich J (2003) Israel allows removal of sperm from dead men at wives' request. BMJ 327: 1187.

21. Dondorp WJ, De Wert GM (2009) Fertility preservation for healthy women: ethical aspects. Hum Reprod 24: 1779-1785.

22. Noyes N, Porcu E, Borini A (2009) Over 900 oocyte cryopreservation babies born with no apparent increase in congenital anomalies. Reprod Biomed Online 18: 769-776.

23. Grifo JA, Noyes N (2010) Delivery rate using cryopreserved oocytes is comparable to conventional in vitro fertilization using fresh oocytes: potential fertility preservation for female cancer patients. Fertil Steril 93:391-396.

24. Homburg R, van der Veen F, Silber SJ (2009) Oocyte vitrification--women's emancipation set in stone. Fertil Steril 91: 1319-1320.

25. Gosden RG, Tan SL, Oktay K (2000) Oocytes for late starters and posterity: are we on to something good or bad? Fertil Steril 74: 1057-1058.

26. Parpalaix v. CECOS (1984) Tribunal de Grande Instance de Creteil (1 Ch. Cir.) August 1, 1984. Gazette du Palais,11-14.

27. Hecht v. Superior Court, 20 Cal. Rptr. 2d 275 (1993)

28. Stevenson-Popp SC (2003) "I have loved you in my dreams": Posthumous reproduction and the need for change in the Uniform Parentage Act. Catholic University Law Review 52: 727-759.

29. Lopez R (2010) Life after death: Murder victim's mom plans his grandson. WFAA-TV.

30. Ethics Committee of the American Society for Reproductive Medicine (2004) Posthumous reproduction. Fertil Steril 82: S260-S262.

31. Hall v. Fertility Institute of New Orleans, 647 So.2d 1348 (La. 1994).

32. Beem $P$ (2004) Where does a man stand on issues of assisted reproduction, surrogacy, artificial insemination within lesbian relationships and posthumous conception? Aust J Fam Law 18: 41-62.

33. Benshushan A, Schenker JG (1998) The right to an heir in the era of assisted reproduction. Hum Reprod 13: 1407-1410.

34. Simpson B (2001) Making 'bad' deaths 'good': The kinship consequences of posthumous conception. Journal of the Royal Anthropological Institute 7: 1-18.

35. Dye JL (2008) Fertility of American women: 2006. Current Population Reports (P20-558). U.S. Census Bureau, Washington, DC, USA.

36. Abma JC, Martinez GM (2006) Childlessness among older women in the United States: Trends and profiles. Journal of Marriage and Family 68: 1045-1056.

37. Robertson JA (1994) Posthumous reproduction. Indiana Law J 69: 1027-1065.

38. Cannold L (2003) Who owns a dead man's sperm? Journal of Medical Ethics 30: 386 .

39. Parker MJ (2004) 'Til death us do part: the ethics of postmortem gamete donation. J Med Ethics 30: 387-388.

40. Spriggs M (2004) Woman wants dead fiancé's baby: who owns a dead man's sperm. J Med Ethics 30: 384-385
41. Laurance $\mathrm{J}$ (1998) Mother wants to bear child from dead son's sperm. The Independent.

42. James SD (2010) Sperm retrieval: Mother creates life after death. ABC News.

43. Dhanoolal v. United States Department of the Army, No. 4:08-CV-42(CDL) (Middle District of Georgia, 2008).

44. Raziel A, Friedler S, Strassburger D, Kaufman S, Umansky A, et al. (2010) Using sperm posthumously: national guidelines versus practice. Fertil Steril 94 1154-1156.

45. Goldberg M (2011) Made in heaven. Tablet

46. Zarchin T (2011) Parent ask court to allow use of dead son's sperm. Haaretz.

47. (1995) New York Hospital Guidelines for Consideration of Requests for Postmortem Sperm Retrieval.

48. Waksberg J (1978) Sampling methods for random digit dialing. Journal of the American Statistical Association 73: 40-46.

49. Pew Research Center (2012) Assessing the representativeness of public opinion surveys.

50. U.S. Census Bureau, Current Population Survey (2011) Table A1: Marital status of people 15 years and over, by age, sex, personal earnings, race, and Hispanic origin.

51. U.S. Census Bureau (2012) State and country QuickFacts.

52. Pew Forum on Religion and Public Life (2008) U.S. Religious Landscape Survey: Religious beliefs and practices. Diverse and politically relevant. Washington, DC, USA

53. Ganong LH, Coleman M (2006) Multiple segment factorial designs. Journal of Marriage and Family 68: 455-468.

54. Hsieh HF, Shannon SE (2005) Three approaches to qualitative content analysis. Qual Health Res 15: 1277-1288.

55. Landis JR, Koch GG (1977) The measurement of observer agreement for categorical data. Biometrics 33: 159-174.

56. Kaba R, Sooriakumaran $P$ (2007) The evolution of the doctor-patien relationship. Int J Surg 5: 57-65

57. Lofquist D, Lugaila T, O'Connell M, Feliz S (2012) Households and families: 2010. (Brief Report No. C2010BR-14).U.S. Government Printing Office Washington, DC, USA

58. Sayer L, Gornick J (2012) Cross-national variation in the influence of employment hours on child care time. European Sociological Review 28: 421 442

59. Cheng AT, Chen TH, Chen CC, Jenkins R (2000) Psychosocial and psychiatric risk factors for suicide. Case-control psychological autopsy study. $\mathrm{Br} J$ Psychiatry 177: 360-365.

60. Rubenowitz E, Waern M, Wilhelmson K, Allebeck P (2001) Life events and psychosocial factors in elderly suicides--a case-control study. Psychol Med 31 : 1193-1202.

61. Link BG, Phelan JC (2006) Stigma and its public health implications. Lance 367: 528-529.

62. Pescosolido BA, Martin JK, Long JS, Medina TR, Phelan JC, et al. (2010) "A disease like any other"? A decade of change in public reactions to schizophrenia, depression, and alcohol dependence. Am J Psychiatry 167: 1321-1330.

63. Cooper AE, Corrigan PW, Watson AC (2003) Mental illness stigma and care seeking. J Nerv Ment Dis 191: 339-341.

64. Moskos MA, Olson L, Halbern SR, Gray D (2007) Utah youth suicide study: barriers to mental health treatment for adolescents. Suicide Life Threat Behav 37: $179-186$
This article was originally published in a special issue, Ethics: Reproductive Technologies handled by Editor(s). Dr. Stephen Napier, Villanova University, USA 